\title{
Still Disease
}

National Cancer Institute

\section{Source}

National Cancer Institute. Still Disease. NCI Thesaurus. Code C61278.

An inflammatory disorder most often affecting children. It is characterized by the presence of arthritis, salmon-colored rash, spiking fevers, fatigue, and sore throats. 